\section{Novel Spin Labeled Azacrown Ethers}

George Sosnovsky* and Jan Lukszo

Department of Chemistry,

University of Wisconsin-Milwaukee,

Milwaukee, Wisconsin 53201 USA

Z. Naturforsch. 40b, 1586-1588 (1985); received May 15, 1985

Azacrown Ethers, ESR Spectra, Synthesis, Nitroxyl Radical

Four novel spin labeled azacrown ethers containing either endo- or exo-cyclic nitroxyl moieties were synthesized by short and convenient routes. These compounds should be of interest in biological studies of membranes using ESR spectroscopy.

The ability of crown ethers [1-4] and cryptands [5-7] to selectively complex ions and neutral molecules has been the subject of extensive studies over the past two decades. One of the most important problems under investigation was the transport of ionic species through membranes in biological systems [8]. Of several transport mechanisms proposed and demonstrated in natural and artificial systems, the coupled transport mediated by mobile carriers (ionophores) appears to be one of the simplest [8]. In such a system a flux of one ion, typically proton, moving down its concentration gradient effects the transport of the desired alkali ion up its concentration gradient. This cation-proton-coupled countertransport has been demonstrated in natural and artificial systems using sodium specific antibiotic monensin [9] and calcium specific lascalocid (X-537 A) and calcimycin (A 23187) [10-13].

Recently, it was suggested by Keana and coworkers [14] that the nitroxyl spin labeled crown ethers and cryptands may find an application in monitoring the concentration of alkali and alkaline earth metal ions in aqueous solutions by the ESR spectroscopy. The high sensitivity of the ESR method, coupled with its use in nontransparent systems would present certain advantages over the existing methods [14]. Several nitroxyl spin labeled crown ethers and two spin labeled cryptands have been reported in recent years $[8,14-18]$. Some of the reported structures are represented by derivatives of the benzo- or dibenzo18-crown-6 $[15,16]$ with nitroxyl moieties attached either by an ester or amide linkage and the nitroxyl group located in a relatively distant position from the cavity of the molecule. Keana and coworkers [14] described the syntheses of two spin labeled crown

* Reprint requests to Prof. Dr. G. Sosnovsky.

Verlag der Zeitschrift für Naturforschung, D-7400 Tübingen 0340-5087/85/1100-1586/\$ 01.00/0 ethers and two cryptands in which the nitroxyl group. in certain conformation, is directed toward the cavity of the molecule. These authors investigated [14] the complexing properties of such compounds and the effect of the complexed metal ion on the $\mathrm{a}_{\mathrm{N}}$ splitting constant in the ESR spectra. Interestingly, no significant change in $\mathrm{a}_{\mathrm{N}}$ was observed for the metal complexes as compared to the free complexon.

Our interest in the area of the spin labeled crown ethers as probes for trans-membrane transport in biological systems led us to design several novel structures $(\mathbf{3} \mathbf{a}, \mathbf{b} ; \mathbf{6} \mathbf{a}, \mathbf{b})$. Thus, in structures $\mathbf{3} \mathbf{a}$ and $\mathbf{3 b}$, the nitroxyl moiety is attached to the ring nitrogen by a carbon-nitrogen bond, whereas in $\mathbf{6 a}$ and $\mathbf{6 b}$ the ring nitrogen is part of the nitroxyl moiety providing the shortest possible distance between the complexed ion and the unpaired electron. It is expected that the former compounds $(\mathbf{3 a}, \mathbf{b})$ are definitely basic and good proton acceptors, whereas the latter compounds $(\mathbf{6 a}, \mathbf{b})$ are less basic [19] and. hence, weaker proton acceptors. Consequently, these novel monoazacrowns $(\mathbf{3 a}, \mathbf{b} ; \mathbf{6 a}, \mathbf{b})$ could not only complex alkali metal ions [20] but, in addition. could also act as proton acceptors and carriers in biological systems.

The synthesis of the crown ethers $\mathbf{3 a}$ and $\mathbf{3 b}$ was accomplished by the reaction of the appropriate tosylates 1a [21] and 1b [21] with the spin labeled diethanolamine 2 [22] in the presence of sodium hydride, in dimethylformamide solution $\left(25^{\circ} \mathrm{C}\right.$, $24 \mathrm{~h})$.

The crude products were isolated by extractive workup and purified by flash chromatography [23] on silica gel using a mixture of chloroform and methanol $(9: 1, \mathrm{v} / \mathrm{v})$ as eluants. The pure products were obtained in the form of red, thick oily liquids with the following analytical data (\% yield, mass spectroscopy-chemical ionization mode, IR $v_{\max }$, microanalyses, and ESR): 3 a [45\%, $374(\mathrm{M}+1,100)$; IR $(\mathrm{KBr}) v_{\max }=1124,1359,2863,3500-3600 \mathrm{~cm}^{-1}$.

$\mathrm{C}_{19} \mathrm{H}_{37} \mathrm{~N}_{2} \mathrm{O}_{5} \times 1 / 2 \mathrm{H}_{2} \mathrm{O}(382.52)$

$$
\text { Calcd C 59.65 H } 10.01 \quad \mathrm{~N} 7.32 \text {, }
$$

Found C 59.89 H $10.10 \quad$ N 7.12.

ESR -3 lines, $\mathrm{a}_{\mathrm{N}}=15.5 \mathrm{G}$ (toluene)], $\mathbf{3 b}[42 \%$. $418(\mathrm{M}+1,100)$; IR $(\mathrm{KBr}) v_{\max }=1120,1353,2865$. $2935,3500-3600 \mathrm{~cm}^{-1}$.

$$
\begin{array}{ccccc}
\mathrm{C}_{21} \mathrm{H}_{41} \mathrm{~N}_{2} \mathrm{O}_{6} & \times 1 / 2 \mathrm{H}_{2} \mathrm{O} & (426.57) & \\
\text { Calcd } & \mathrm{C} 59.12 & \mathrm{H} & 9.92 & \mathrm{~N} 6.57, \\
\text { Found } & \mathrm{C} 59.42 & \mathrm{H} 10.00 & \mathrm{~N} 6.41 .
\end{array}
$$

ESR - 3 lines, $\mathrm{a}_{\mathrm{N}}=15.5 \mathrm{G}$ (toluene)]. Characteristic bands at $3500-3600 \mathrm{~cm}^{-1}$ in IR spectra of $\mathbf{3}$ a and $\mathbf{3 b}$, as well as microanalyses clearly indicate the presence of one molecule of water for two molecules 


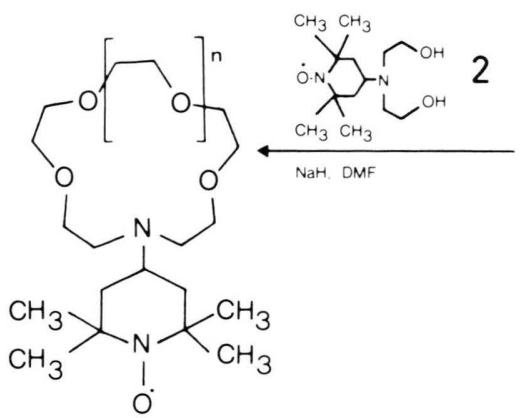

$3 a: n=1$

$3 b: n=2$

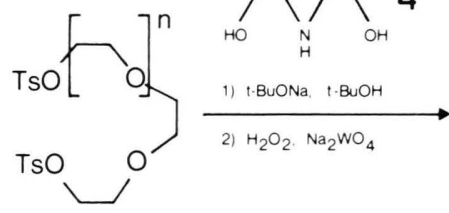

1a: $n=1$

lb: $n=2$

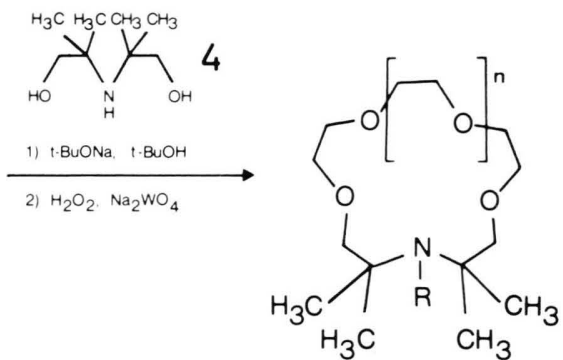

$5 a: n=1, R=H$

5b: $n=2, R=H$

6a: $n=1, R=0$

$6 b: n=2, R=\dot{0}$ of the crown ether, suggesting a "sandwich complex". This water molecule was strongly bonded since it could not be removed by vacuum drying at $60^{\circ} / 0.01$ torr.

Synthesis of the spin labeled crown ethers $\mathbf{6 a}$ and 6b was accomplished by a two step procedure (Scheme). Thus, the monoazacrown ethers $\mathbf{5 a}$ and 5 b were obtained in $47 \%$ and $46 \%$ yield, respectively, by the reaction of substituted diethanolamine 4 [24] with the appropriate tosylates $\mathbf{1 a}$ [21] and $\mathbf{1 b}$ [21] in $t$-butyl alcohol solution, in the presence of sodium $t$-butoxide [25]. These intermediates were purified by a Kugelrohr distillation (5a, b.p. $102-106{ }^{\circ} \mathrm{C} / 0.015$ torr; $\mathbf{5 b}$, b.p. $124-126{ }^{\circ} \mathrm{C} /$ 0.03 torr) and characterized by mass spectrometry $[\mathbf{5} \mathbf{a}, m / e=276(\mathrm{M}+1,100) ; \mathbf{5 b}, m / e=320(\mathrm{M}+1$, $100)$ ]. Oxidation of $\mathbf{5} \mathbf{a}$ and $\mathbf{5} \mathbf{b}$ in aqueous solutions using a $30 \%$ hydrogen peroxide in the presence of catalytic amounts of sodium tungstate gave $\mathbf{6 a}$ and $\mathbf{6 b}$, respectively. In spite of an excess of the oxidant and prolonged reaction times, the transformations were incomplete. Extractive workup, followed by flash chromatography [23] gave the pure products $6 \mathbf{a}$ $(31 \%)$ as an orange solid, m.p. $46-47^{\circ} \mathrm{C}$, and $6 \mathbf{b}$ $(34 \%)$ as an orange, thick oily liquid. These mate- rials were characterized by mass spectroscopy, IR, microanalyses, and ESR, resulting in the following values: 6a $\left[291(\mathrm{M}+1,100), 290(\mathrm{M}, 90)\right.$; IR $v_{\max }=$ $1115,1141,1356,2900-2980 \mathrm{~cm}^{-1}$.

$\mathrm{C}_{14} \mathrm{H}_{28} \mathrm{NO}_{5}$ (290.38)

$\begin{array}{llll}\text { Calcd } & \text { C } 57.90 & \text { H } 9.72 & \text { N } 4.82, \\ \text { Found } & \text { C } 57.82 & \text { H } 9.94 & \text { N } 4.66 .\end{array}$

ESR -3 lines, $a_{N}=15 \mathrm{G}$ (toluene) $]$ and $\mathbf{6 b}[334$ $(\mathrm{M}, 100), 335(\mathrm{M}+1,88) ; \mathrm{IR} v_{\max }=755,1118,1354$, $2860-2990 \mathrm{~cm}^{-1}$.

$$
\begin{array}{cccc}
\mathrm{C}_{16} \mathrm{H}_{32} \mathrm{NO}_{6}(334.43) & & \\
\text { Calcd } & \mathrm{C} 57.46 & \mathrm{H} 9.65 & \mathrm{~N} \\
\text { Found } & \mathrm{C} 57.31 & \mathrm{H} 9.68 & \mathrm{~N} 3.99 .
\end{array}
$$

$\mathrm{ESR}-3$ lines, $\mathrm{a}_{\mathrm{N}}=15 \mathrm{G}$ (toluene)]. In contrast to the $\mathbf{3} \mathbf{a}$ and $\mathbf{3} \mathbf{b}$ compounds $\mathbf{6} \mathbf{a}$ and $\mathbf{6} \mathbf{b}$ were isolated in the unhydrated form as evident from microanalyses and the absence of the water $\mathrm{O}-\mathrm{H}$ stretch peak in the IR spectra.

This study was conducted pursuant to a contract with the National Foundation for Cancer Research. The author, G. S., thanks the Graduate School of the University of Wisconsin-Milwaukee for the J. D. and D. Shaw Awards in 1983 and 1984
[1] E. Weber and F. Vogtle, Top. Curr. Chem. 98, 1 (1981).

[2] D. J. Cram and K. N. Trueblood, Top. Curr. Chem. 98, 43 (1981).

[3] F. DeJong and D. N. Reinhoudt, Adv. Org. Chem. 17, 279 (1981).

[4] J. J. Christensen, D. J. Eatough, and R. M. Izatt, Chem. Rev. 74, 351 (1974).

[5] J.-M. Lehn, Acc. Chem. Res. 11, 49 (1978).

[6] J.-M. Lehn, Pure Appl. Chem. 50, 871 (1978).
[7] E. Blasius and K.-P. Janzen, Top. Curr. Chem. 98, 163 (1981).

[8] T. M. Fyles, C. A. McGavin, and D. M. Whitfield, J. Org. Chem. 49, 753 (1984).

[9] E. M. Choy, D. F. Evans, and E. L. J. Cussler, J. Am. Chem. Soc. 96, 7085 (1974).

[10] B. C. Pressman and N. T. de Guzman, Ann. N. Y. Acad. Sci. 264, 373 (1975)

[11] W. J. Malaisse, I. Valverde, G. Devis, G. Somers, and E. Couturier, Biochimie 61, 1185 (1979). 
[12] E. Couturier and W. J. Malaisse, Biochimie 62, 177 (1980).

[13] J. Bolte, C. Demuynck, G. Jeminet, J. Juillard, and C Tisier, Can. J. Chem. 60, 981 (1982).

[14] J. F. W. Keana, J. Cuomo, L. Lex, and S. E. Seyedrezai, J. Org. Chem. 48, 2647 (1983).

[15] M. P. Eastman, D. E. Patterson, R. A. Bartsch, Y. Liu, and P. G. Eller, J. Phys. Chem. 86, 2052 (1982).

[16] K. Ishizu, H. Kokohama, and K. Mukai, Chem. Lett. 1978, 227.

[17] H. Dugas and M. Ptak, J. Chem. Soc. Chem. Commun. 1982, 710 .

[18] H. Dugas, P. Keroack, and M. Ptak, Can. J. Chem 62, 489 (1984)
[19] E. G. Rozantsev and E. G. Gintsberg, Izv. Akad. Nauk SSSR, Ser. Khim. 1966, 571.

[20] R. A. Schultz, D. M. Dishong, and G. W. Gokel. Tetrahedron Lett. 1981, 2623.

[21] J. Dale and P. O. Kristiansen, Acta Chim. Scand. 26, 1471 (1972).

[22] D. Kikelj and S. Pecar, Synthesis 1984, 125.

[23] W. C. Still, M. Kahn, and A. Mitra, J. Org. Chem. 43, 2923 (1978)

[24] J. T. Lai, Synthesis 1984, 122.

[25] H. Maeda, Y. Nakatsuji, and M. Okahara, J. Chem. Soc. Chem. Commun. 11, 471 (1981). 